\title{
SUCCESS ATTRIBUTES OF REGIONAL NATURAL RESOURCE MANAGEMENT
}

\author{
J.A.WILLIAMS ${ }^{1}$, R.J.S. BEETON ${ }^{2}$ \& G.T. MCDONALD ${ }^{\dagger}$ \\ ${ }^{1}$ CRC Irrigation Futures/University of New England, Australia. \\ ${ }^{2}$ University of Queensland, Australia.
}

\begin{abstract}
The complexity of natural resource management (NRM), which is socially an evolving 'discipline of disciplines', creates challenges for society. With the continual degradation of the natural resource base it can be hypothesised that the past and present approaches to NRM in Australia have failed. NRM is recognised in the 21st century as having assumed importance as a development strategy because of the claims that it can contribute towards sustainable livelihoods; thus NRM has two facets: the natural resource base and the institutional arrangements required to maintain this base. Australia is presently going through a transformation with the evolution of a regional NRM systems approach. This paper reports a hypothesised model of a sustainable regional NRM system for Australia.

Keywords: key elements, model, success attributes, sustainable regional NRM system.
\end{abstract}

\section{INTRODUCTION}

Natural resource management (NRM) popularly has come to mean the sustainable utilisation of all natural resources (land, water, air, minerals, forests, fisheries, wild flora and fauna) [1]. This assumes that these resources provide the ecosystem services that underpin human life [2]. NRM until relatively recently had its main focus on soils, hydrology, agronomy, biology, ecology and other 'natural' dimensions [3]. The concept of sustainable NRM has often been simplistically presented either as a technical-ecological issue or as an economic issue; however, if either of these approaches were sufficient, natural resource degradation problems would be relatively easy to solve [4]. Lachapelle et al. [5] see it as an evolving discipline with new paradigms being recommended by many academics, planning theorists and practitioners. NRM is now recognised as having importance as a development strategy because of the claims that it can contribute towards sustainable livelihoods. Therefore, NRM has two facets, the natural resource base and the institutional arrangements required to maintain this base. In reality NRM is attempting to respond to diverse interests in sharing limited resources and is, in essence, a human conflict that should be managed as such [6]. NRM is trans-disciplinary with social, ecological and economic factors inextricably linked [7]. To address one necessitates intervention in another. This paper presents a multi-dimensional model of a sustainable regional NRM system for Australia sourced from theory and practice. The model identifies the critical success attributes required and suggests a multi-disciplinary approach with contributions from planning/geography, political science, sociology, economics, psychology, ecology and agri-environmental systems as essential for the exploration of the complexities and success attributes of NRM.

\footnotetext{
†Professor Geoff McDonald was one of Australia's most prominent thinkers in planning and its application to natural resource management. Not only did he give effect to this through his many postgraduate students and personal scholarship he also applied his knowledge through public service by serving on in many public policy and decision-making roles. Geoff is greatly missed by all who knew him.
}

(C) 2008 WIT Press, www.witpress.com

ISSN: 1743-7601 (paper format), ISSN: 1743-761X (online), http://journals.witpress.com DOI: $10.2495 /$ SDP-V3-N3-203-222 


\subsection{Sustainable regional NRM defined}

A sustainable regional NRM system's ability to achieve its objectives requires components, characteristics and relationships. Superficially the NRM Australian literature suggests [1] that NRM is being driven towards a regional approach by the evolution of new delivery mechanisms; however, many more factors are influencing this. Privatisation trends, growing fiscal constraints at state levels, globalisation, neo-liberalism, reorganisation of the roles of the state and the market, reorganisation of society around a different vision of development and democratic decentralisation of natural resources are proposed as the main drivers for a regional approach [8]. Natural resources and the environment along with demographics, science and technology, global economy and globalisation, national and international governance, and future conflict have been identified as key global drivers between 2003 and 2015 [9].

Regional NRM is best defined as the intermediate between the economy and the formal institutions of the state used to deliver ecologically sustainable development; therefore, regional NRM has a responsibility for both the sustainable management of natural resources and the building of civil society $[8,10]$. In essence regional NRM proposes a new form of democracy focusing on regional community participation in the form of regional decentralisation and devolution to facilitate sustainable NRM. This new form of democracy comes in a variety of institutional structures and is often referred to as community-based NRM with the common characteristics of decentralisation and devolution underpinning this relatively new paradigm.

\subsection{Identifying the key elements of NRM}

The many attributes and their disciplinary sources demonstrate the complexity of sustainable NRM. Ascher [11] suggests that identifying the key elements creates a means to better cope with complexity and the effects of organisational interests, which can assist with the delivery of sustainable NRM. To progress the model development, key elements of the nature of the system and the groupings of cross-disciplinary factors were considered to sequence the progression of the development of a sustainable regional NRM system. This sequence was based on the hypothesis that people and their attitudes drive sustainable NRM outcomes. The key elements hypothesised as progressing an analysis of sustainable NRM were:

1. people and attitudes,

2. organisations and their governance,

3. the third way: regionalism the new panacea, and

4. building societies' capacity for sustainable NRM: 'means to ends'.

The following discussion will provide an overview of sustainable NRM from both an international and an Australian perspective, further pinpointing the common themes and proposed success attributes within the key elements of a sustainable regional NRM system. The discussion will culminate with the introduction of a new model for sustainable regional NRM in Australia built from these critical success attributes.

\section{INTERNATIONAL TRENDS IN SUSTAINABLE NRM}

The recent Millennium Ecosystem Assessment [12] hypothesises that human activity is putting such a strain on the natural functions of the earth that the ability of the planet's ecosystems to sustain future generations can no longer be taken for granted. Throughout history humans have lived on the 
earth's sustainable yield, yet now we consume the endowment itself with humanity's collective demands estimated as first surpassing the earth's regenerative capacity around 1980 [13]. Stewart [14] claimed that the evidence of ecological crisis was compelling as was detailed in the State of the Planet 2004 report which found that humans are using fresh water, forests, rangelands and oceanic fisheries at a rate which is undermining the ecological processes that support these resources. With this are signs of the early stages of the greatest loss of plant and animal species in 65 million years and global climate change. The 'tragedy of the commons' [15] argues that human communities do not have an interest in promoting common good and that open access to resources for human communities would result in resource exploitation.

Such insights have led to the justification for NRM policies that promoted strong regulatory control [16], strong central management or complete privatisation of resources [17] as the answer. Continued human population growth and the subsequent natural resource decline affecting the globe have resulted in socio-economic institutions attempting to control ecosystems with command and control type responses to erratic or surprising ecosystem behaviour. A more recent approach to managing the commons has been the development of adaptive management [18], which attempts to incorporate the results of management practices and societal values into each succeeding action. This philosophy is based on informed and widespread empowerment that is required to complement centralised management regimes [16]. Holling and Meffe [19] describe the approach of command and control as the 'pathology of natural resource management', where they argue that the pathology afflicts institutions managed by command and control as well as the ecosystems and that institutions managed by command and control have low resilience to new changes. They also warn that institutions that are dominated by cultures of control, resistance to new ideas and unwillingness to change contribute to the ongoing degradation of ecosystems. These central style management and privatisation strategies are proving to be unsuccessful as the unsustainable use of natural resources continues to escalate. Stewart [14] argues that 30 years later the metaphor of the commons still has hold on the collective imagination, but now the 'invisible hand' of the market has replaced the 'heavy hand' of state intervention as the favoured means of averting the tragedy.

\subsection{The evolution of NRM approaches}

To better understand the evolution of managing the commons requires historical context. Approaches to environmental harms pre-1960s (apart from soil conservation measures) were predominantly through private remedies in tort and nuisance. Early environmental policy depended on science with mixed results. Stewart [14] provides insight into the first two waves of environmental concern, from command and control adhockery to a more sustainable development style approach. The new focus on participative community-based NRM is a third option to 'command and control' and 'marketbased solutions'. Community-based NRM is an approach to managing renewable resources and can encompass a large amount of experimentation and regional variation [20]. At the core of communitybased NRM are management rights that enable communities to become partners in and greater beneficiaries of the management of local resources. Ribot [21] claims that decentralisation reforms change the institutional infrastructure for local NRM and in some cases creates an institutional basis for more popular and participatory management and use of natural resources. Community-based NRM is a way of increasing both efficiency and equity in NRM. Twenty years ago community-based NRM was regarded as an oxymoron by most policy makers and practitioners due to concerns that local people could not be trusted with natural resources because of self-interest [22]. A study of community-based NRM and its relationship to community development in British Colombia [23] found that this approach offers solutions that are often missed by centralised systems and research is 
finding that communities that are able to play a meaningful role in management have in many cases developed ways to prevent overexploitation of local resources. Such an example of participatory NRM is seen to offer an opportunity to institutionalising and scaling up local participation. However, decentralisation requires both power transfers and accountable representation as key requirements for equity, justice and efficiency [4]. Johnson [24] claims that decentralised democracy in its most undiluted form is a process that aims to extend and improve the authority of groups that are traditionally under-represented in the market and the state.

\subsection{Recent findings of decentralised NRM approaches internationally}

How are these new participatory approaches to NRM and broader policies of decentralisation faring? Their drivers of devolving management and responsibility from the state to users are becoming more widespread internationally in response to the performance deficiencies of government agencies using command and control and the fiscal crisis of the state. The relevance and advantages of devolution and participatory approaches in NRM recognises that community resource management produces desirable outcomes under certain conditions, with local communities seen as good resource managers with local-specific knowledge, local adaptability, low transaction costs, low dependency on resources and having a conservation ethic. However, there are potential problems with devolution and participatory approaches in NRM including conflicts with informal rules and traditional hierarchies, communities not being homogenous and hence they do not act in the interest of the whole, rent seeking by elites and exclusion of marginal groups. In addition, communities may have insufficient knowledge about ecological relationships and conservation methods and devolution does not necessarily solve inter-community, regional and international externalities [25]. An international review of the theoretical issues of decentralised NRM found that there are many views ranging from the Malthusian argument to historical and cultural ecology, to neo-traditionalism of the fate of humankind and the natural resources of the earth [7]. A recent addition to these views is that of environmental entitlements [26].

Common to all these views are four major issues in NRM [7], namely:

- the state versus the individual and the community in resource management (i.e. property rights);

- population growth and carrying capacity, including the conundrums that population growth can lead to innovation in agriculture and better resource use and depopulation can lead to ecological degradation;

- market pressures transforming relations of production and resource use patterns;

- the 'quality' of local scientific and other knowledge relevant to NRM.

In the face of this complexity Farrington and Baumann [7] argue that there is a need for society as a whole to understand the natural processes in our physical environmental. The process through which environmental issues can become an object of thought are eventually social, hence the need for combining the analysis of local 'place-based' physical and human processes with those of other 'non-place-based' processes [7]. The experiences of community-based NRM in Botswana [27] identified the required process changes needed by communities to obtain their constitutions through legal structures that recognise their heterogeneous ethnic composition. The community-based approach is often constrained by governments' mistrust of local communities; however, governments need to understand that authority without responsibility is meaningless and obstructive and constrains effective sustainable NRM [21]. A study of organisational development and NRM in the Central Honduras [28] found that both external and internal organisations play important and 
complementary roles in fostering a more sustainable and productive use of natural resources, with external organisations able to play a catalytic role as long as facilitation is not undermining local initiative. This study highlighted the challenge for policy makers and programme managers to:

- identify and exploit cases where synergy exists between external and local organisation development;

- be cautious about intervening in a way that displaces local initiative;

- focus on effort of activities that have significant social benefits that are not being addressed adequately by private action;

- increased investment by external actors in understanding the extent and roles of local organisations.

Ribot [21] proposed that most of the recent 'decentralisation' reforms are characterised by insufficient transfers of powers to local institutions, often under tight central government oversight, and many of the local institutions are neither representative nor accountable to their local communities. These aspects reinforce how secure powers and accountable representation should be major factors of democratic decentralisation as transferring power without accountable representation is dangerous and establishing accountable representation without powers is empty [21].

A study analysing negotiation approaches in NRM in a case study of crop-livestock conflicts in Sri Lanka [29] found that participatory approaches in NRM are increasingly being criticised for their tendency to neglect power relations and conflicts of interest. The study concludes that negotiation approaches should be used as a strategy to overcome shortcomings, with game theory modelling providing useful insights into the incentive structure of resource users and politicians involved in the negotiation process. A review of international participatory NRM projects [30] identified the importance of recognition of the role of public participation; however, the case studies identified that there was little indication in NRM institutions of the types of participatory processes that ought to be set up, the role of stakeholders, the selection criteria for stakeholders and clarity of methods to be used. This review identified four key drivers of process design that require addressing as: process goals, power structures, process directions and stakeholder numbers.

Knox and Meinzen-Dick [31], commenting on factors that contribute to effective devolution programmes in the forestry, fisheries, irrigation and rangeland sectors internationally, found that despite the theoretical advantages of user management and the impetus for strong devolution policies, the actual outcomes of devolution programmes in various sectors and countries have been mixed with proponents of devolution of rights to resource users struggling to understand better what elements facilitate collective action and what factors hinder its creation and sustainability. McLain and Jones [32] challenged community definitions of sustainable NRM and claim that when influence and control over natural resources shift towards local communities, the definition of 'local community' determines who will share in this power and who will benefit from resource management and allocation decisions. Defining the bounds of local communities and who constitutes insiders and outsiders remains problematic with different stakeholder agendas possibly leading to conflicts at the level of implementation [33].

The debate surrounding community-based conservation [34] illustrates that leadership is important as a factor that contributes to effectiveness and success. Recent debate on the political dimensions of decentralising NRM indicate that policy inconsistencies, particularly of poorer nation states, are an issue particularly where the same international agencies that prescribe economic policies that lay claim on and exploit valuable natural resources also advocate community-based NRM approaches to strengthen both the resource base and the livelihoods. Other problems associated with decentralised NRM involved structural inequalities, property rights and power, including financial and judicial powers [35]. Leach and Scoones [26] found that despite all the emphasis given to 
community-based approaches within recent environmental and development policy debates, the actual results in practice are often disappointing. Underlying the current problems Leach and Scoones [26] found a set of assumptions based on community, environment and the relationship between them and the domination of Malthusian perspectives that tend to frame the problem in terms of an imbalance between social needs and aggregate resource availability. They conclude alternative approaches are required to look at the politics of resource access and control among diverse social actors, who may have different priorities. They characterise change as a direct result of negotiation or contestation between social actors. The diversity of the institutions that shape differentiated NRM groups provides some clues for good NRM approaches. Lane and McDonald [36] identify six key problems with the community-based environmental planning approach, namely the conceptualisation of 'community', problems of inequality, the organisational capacity and efficacy of community groups, the scale of community-based environmental planning, the types of knowledge utilised by these communities, and the potential for parochial concerns to dominate the priorities and agenda of community organisations.

\subsection{Common themes from the international experience}

Common themes appear from international experiences, the important attributes in the success of sustainable NRM as: stakeholders and their communities, organisations and their governance, power relations, conflicts of interest, negotiation processes between actors, participatory processes, collective action, relationships, devolution and stakeholder selection. NRM decisions made by individuals, civil society and the state involve questions of economic efficiency, environmental effectiveness, equity and political legitimacy. A multi-disciplinary approach is required to understand NRM decisions that seek to identify legitimate and the context-sensitive institutional solutions that produce equitable, effective, efficient and enduring NRM outcomes [33]. To better understand the complexities of organisational behaviour in NRM requires scoping of the organisations' reactions to complexity and uncertainty inherent in NRM. This requires, firstly, identification of the organisational interests of the agencies and formal institutions in NRM, oversight, policymaking, management and exploitation. And, secondly, how the efforts of all the actors can be integrated in an effective institutional arrangement that brings about sustainable NRM. We conclude that sustainable NRM issues and solutions hinge on better understanding of the diverse actors and their organisations and the relations of power of this complex system.

\section{NRM APPROACHES IN AUSTRALIA}

While the investment in NRM in Australia, both in financial and regulatory terms, is at its highest point ever, Australia's natural systems remain in decline [37]. The response to this dilemma has been the evolution of a regional NRM systems approach across the country since 2002.

\subsection{Background of NRM approaches in Australia}

Dunlap [38] describes Australia as lands now littered with the wrecks of earlier generations' hopes and dreams, and has identified the different phases of Australia's relationship with nature as being from Aboriginal times to occupation in the late 1700s, to reaching limits from 1850 to 1900, to the diffusion of ecology from 1948 to 1967. Since European settlement new and old disciplines have been integrated so that the history of NRM in Australia presents itself in a dissected form. NRM has been merged with agricultural aspects of soil conservation [39, 40], conservation and environment [41], resource degradation [42, 43], ecological thought and action [44], environmental history and 
policy [38, 45], the social sciences and the many versions of landcare and catchment management approaches [39, 40,46-48] all coalescing into ever widening fields of study and action. These disciplines often failed to acknowledge other players' aspirations and attempts at NRM with all failing to recognise that Australia was in 1770 a series of aboriginal commons with empirically derived management systems [49] many of which maintained ecological disclimaxes.

In the late 1980s the Australian Landcare movement emerged and was coupled with a catchment management approach with public participation and significant government and community investment through programmatic approaches such as the National Soil Conservation Program (NSCP), the National Landcare Program (NLP) and the Natural Heritage Trust Phase 1 (NHT1). This period is often posited as the most significant new direction in NRM since European settlement [50]. Coupled with this new approach has been the increase of national and state NRM legislation. From the early 1990s till 2002 there was significant investment in evaluation of the effectiveness and efficiency of these various NRM programmatic approaches with 65 completed evaluations of NHT1 alone [51]. Results from the various reviews of NRM approaches generated a plethora of national discussion papers, reports and proposed models [4, 37, 52-59]. These are assumed to have contributed to the development of a new approach towards NRM in the form of the second phase of the trust known as NHT2 together with the National Action Plan for Salinity and Water Quality (NAP). These programmes are considered to be the main delivery mechanisms for sustainable NRM approaches in Australia between 2002 and 2008 leading to the formation of 56 regional NRM bodies covering all of Australia.

\subsection{Findings from decentralised NRM approaches in Australia}

While there are demonstrated outcomes in awareness raising of NRM issues from these communitybased NRM programmes, the objective of reversing natural resource decline has not been achieved [60]. The final evaluation of NHT1 [61] reflected repetitive themes found in most evaluations of these programmatic approaches since the early 1990s. This evaluation found that the Trust has had a significant impact in terms of raising awareness, changing attitudes and increased understanding and knowledge of environmental protection, NRM and sustainable agriculture and has also improved the levels of communications, cooperation and trust between stakeholders and built capacity with both the community and the government. However, the evaluation also found that there was a lack of a strategic investment framework, long timeframes for progress in decision-making and administrative processes, small-scale nature of most projects and a focus on on-ground outcomes. The scope of community development and resource condition improvement has been limited due to these and other shortcomings. The Australian National Audit Office (ANAO) found in a review of the administration of the NAP [62] that the administration of the programme has been characterised by delays that have had a flow-on effect for all stages of programme implementation. The ANAO found that it has only been since 2003-04 that substantial investment in on-ground initiatives has occurred. The review also found that the programme had achieved significant institutional change and facilitated planning and specific management action in identified NAP regions recognising that this action and the subsequent achievement of targets will take some years to complete and may be beyond the scope of the programme. Importantly, the review highlights potential programme risks in small, newly established, community-based bodies having primary responsibility for delivering challenging outcomes and managing substantial allocations of Australian Government funds.

An alternative view challenges the appropriateness of NRM bodies as vehicles to address wider societal and landscape problems together with the ability of non-statutory or quasi government organisations to resolve catchment management problems [63]. Decentralised regionalism and 
environmental management in Australia has been criticised to be idealised and naïve to obvious complexities and potential pitfalls [64]. A study of regional delivery of NRM in Australia [65] found that regional groups do not currently fully represent their demographics. This is at odds with the place of democracy in the Australian culture and suggests community disempowerment. McDonald and Morrison [66] identify that severe problems of fragmented policies and uncoordinated implementation potentially undermine NRM in Australia. Alternatively, Yee and Rolfe [67] identified a key benefit of the regional NRM model in Australia as the collaborative, community-driven focus of NRM planning and implementation. However, they claim that this may incur higher transaction and overhead costs than other models. Their concern is whether the current arrangements are a genuine attempt to devolve NRM planning to the regional level or a cost shifting exercise to secure Australian Government funding for NRM programmes. Evaluation of the effectiveness of regional NRM planning processes in the Tropical Savannas of Australia [68] found that there were a number of lessons related to: regional context; linking scales and activities; coordinating regional effort; new roles and responsibilities; the capacity of planners, managers and stakeholders; and bringing knowledge and information together for NRM.

The 2006 Australian Government reviews of regional NRM delivery in Australia found that common repetitive historic issues continued to plague the NRM programmes. The reviews highlighted the need for an outcome focused approach, clarification of roles and responsibilities, appropriate and adequate incentives and resourcing, appropriate coordination, equity in public good cost sharing, established NRM baseline data, and the need for appropriate and consistent monitoring of performance and NRM data. In particular, the regional NRM delivery was considered to lack engagement of key land managers, particularly primary producers and local government. Paradoxically, concurrent with these reviews was the latest survey of on-farm NRM investment, which found that farmers spent over $\$ 3.3$ billion preventing and/or managing NRM issues in just one year [69]. Coupled with this was the estimated $\$ 10.8$ billion greenhouse emission reductions achieved largely at a perceived cost to Australian farmers because of the deployment of legislative tools restricting land clearing [8]. Concerns have been expressed at the lack of recognition of farmers' investments for public good NRM [8].

In addition to these issues is the lack of availability and access to regional NRM information products that can be used for regional, state and national NRM reporting. This has aggravated the lack of clarity about the roles and responsibilities for NRM monitoring and evaluation, particularly between regional NRM bodies and state agencies [70]. The Australian Industry Commission's [56] 'Inquiry on Ecologically Sustainable Land Management' proposed an elaboration of the duty of care and also identified options such as payments to be made to the landholder for the financial costs of conservation management and for forgone economic opportunities recognising the public good of the contributions. The Australian Government House of Representatives' 'Inquiry of Public Good Conservation' [57] recommended that an agreement with the states and territories for, firstly, a commonly accepted definition in principle of a landholder's duty of care and, secondly, that financial assistance be provided directly to landholders for the transition from environmentally degrading land use systems to ecologically sustainable land use systems. The Inquiry also included recommendations such as the removal of disincentives and the provision of tax concessions and rates relief. The Australian Government Productivity Commission [71] found that native vegetation and biodiversity regulations have adversely affected the returns of many landholders by imposing a range of restrictions on farm practice and in some cases the Commission found that the landholders most severely affected by the regulations have often suffered serious personal problems in the face of the resultant marginal viability and sometimes even suffered loss of property [72]. Little change has occurred over the past 9 years as a result of these three important inquiries in terms of equity for rural 
landholders in shared costs of public good NRM outcomes. Consequently, in 2006 the Australian State of Environment report reiterated a number of these problems [73].

\subsection{Common themes from the Australian experience}

Common themes emerging from NRM experiences in Australia identify necessary attributes as: clarification of property rights and duty of care, clarification of roles and responsibilities, change management methods for groups and individuals, credible and legitimate institutions, performance criteria indicators and targets, participative approach, adequate investments, shared costs of public good outcomes, and coordination and integration. Australia demonstrates conclusions to those found internationally in NRM, namely that people and their interactions, power relations and legitimate organisations are key issues to address so that sustainable regional NRM can move forward.

\section{PEOPLE AND ATTITUDES IN SUSTAINABLE NRM: A NEW APPROACH}

In human society a multiplicity of individuals and organisational stakeholders all pursue their own interests often with conflicting goals, political and cultural backgrounds and limited knowledge and awareness of each other's issues. The consequences of these interactions and divergence of interests can produce system failure and NRM is no exception. Now, the human dimension is recognised as important in resource management problems and has to be integrated from the very beginning of the analysis of the problem [74] with an emphasis on communication and persuasion to reconcile conflicting interests and facilitate cooperation [75].

\subsection{Agent-based modelling}

Agent-based modelling [74] is an approach to include the human dimension where people are viewed as agents to describe the behaviour of observed entities and individuals. This tool provides a means to study interactions between societies and their environment by focusing on interactions between the various agents. The strategic interaction between rational players, which produces outcomes with respect to the preferences of these players, is often recognised as a subset of game theory [76]. Agents sense, decide and act and have personality rich behaviours [75, 77]. They have internal states and behavioural rules which may be fixed or changeable through experience and interaction and they interact in an environment that provides resources for their actions [78]. For example reactive agents choose actions directly to their sensed circumstances, while deliberative agents reflect upon alternative courses of action. Social agents communicate and cooperate. Adaptive agents change their behaviour in the light of changing circumstances [79]. Possible relationships between agents can include cooperation, negotiation, subordination and competition. Agents can have different styles of behaviour in leadership, conflict, learning and decision-making [79]. Agents influence each other by providing social approval or disapproval as a trade-off to obtain approval or avoid disapproval. In human society the social rules are formed through a complex set of social norms and conventions and a full understanding of these are required to apply agent-based modelling tactics [80]. Williams [8] identifies 19 different agents required in a sustainable regional NRM system approach.

Agent-based modelling requires the identification and typing of personalities as part of the process of agent identification and there are numerous methods that are well recognised in typing personalities including: The Big Five, the East's five personality types, the four Temperaments, the Enneagram, Myers-Brigg Type Indicator and the Korean typology of personality [8]. Analysts use game theory as a tool whenever confronting situations in which one agent's rational decision-making depends on the expectations about what one or more agents will do, and these game theoretical 
insights can be found among philosophers and political commentators going back to ancient times and is particularly evident in military strategies [76]. Game theory has become a tool in environmental and resource economics, providing a comprehensive framework for the analysis of the fundamental cause of environmental problems within multi-actor decision-making situations characterised by the lack of property rights and the existence of externalities. Agent-based modelling provides the means to identify players, agents and their contextual environment to better understand the nature of the conflict and the styles of intervention required to facilitate change management. Barzilai [81] claims that to successfully change people's behaviour in an organisation you must understand the terms of the psychological contract for those individuals. Wilson [82] identified altruism in humans as culturally determined and claims that for humans the key to behaviour is environment with aggression often an adaptive response to certain kinds of social stress. He also claims that a human individual places themselves first, family second, tribe third and the rest of the world a distant fourth and that humans suffer from a myopic fog with their genes predisposing them to plan ahead for at the most one or two generations.

\subsection{Power relations}

Power relations require identification and understanding of resource conflicts. Game theory processes such as agent-based modelling provide an opportunity to identify the types of power and the relationships of the players and agents. Power can be simply defined as the probability that one agent within a social relationship will be in a position to carry out their own will despite resistance. Power involves one person changing the behaviour of one or more other individuals, particularly if that behaviour would not have taken place otherwise [83]. The variety of human world system structures are conventionally defined in the terminology of power such as non-polarity, unipolarity, bipolarity, tri-polarity, multi-polarity, hegemony and empire, with these terms denoting commandcontrol networks whose network architectures vary in centralisation, shape and complexity of connection. Civilisation [84] and culture [85] seen as networks can provide another approach to viewing power relations.

\subsection{Common themes}

Ostrum [86] identifies that there are circumstances where cooperation and social rules do emerge; however, this appears to be in the minority. Tools to identify and manage conflict are required in regional NRM. Agent-based modelling, player and agent types, human behavioural characteristics, personality trait recognition and the relations of power demonstrate the need to, and suggested methods to, describe a multi-system environment so as to design adequate interventions directed at positive results. In such a context the 'rules of engagement' together with historical and cultural factors need to be considered along with how the community of interest 'undertake their business' before considering intervention. Successful intervention requires: the identification of the players of sustainable NRM, the agents required to bring about positive change, the personality traits required of those agents, scoping of the contextual environment (rules) the players and their agents are working in and scoping of the relations of power that exist. It is crucial to have all the players of NRM included in the conflict resolution process. The success attributes for people and attitudes demonstrate that efficient, effective and enduring sustainable NRM requires: an understanding of the players in the conflict; an understanding of the agents and their motivations, interactions and psychological contracts; the relations of power that exist; the contextual environment of the conflict; an adaptive management approach; and long timeframes. 


\section{HUMAN ORGANISATIONS AND THEIR GOVERNANCE}

Organisations are structured social systems consisting of individuals working together to meet agreed objectives [81]. Institutions are complexes of norms and behaviours that exist over time by serving collectively valued purposes and reflect the long-standing rules and rights governing social and productive behaviour [87]. To achieve sustainable NRM involves a holistic approach incorporating economic, social, environmental and cultural needs and players. This intimates that a 'whole of society' approach is required to succeed. To further understand the complexities of institutions and organisations in sustainable NRM we need to identify the 'organisational players' in this 'whole of society' approach. Governance, which generally refers to the 'rules of the game' of organisations, is to be used in this discussion to create an organisational typology to better understand the contextual environment that the players and agents of sustainable NRM are embedded in. For the purposes of this discussion the 'organisational players' in sustainable NRM have been identified as three distinct groups: government, the corporate sector and civil society (not-for-profit NGOs). Within each of these organisational players are a variety of interest groups and agents; however, the common thread in each of these players is that their own particular governance actually frames their existence, evolution and progress. Importantly, the analysis of each player's governance provides a clear picture of roles and responsibilities. Since the 1990s the governance idea has gradually become a central focus of regional development policy with one of the driving forces behind this development being the politically friendly nature of global-local theory in that it provides local politicians with an external enemy being 'global' and a solution being 'the mobilisation of local agents in development coalitions' [88].

\subsection{Governance}

An overview of the findings of a literature review of the governance attributes of the three sectors [8] is provided in Table 1. Given the different organisational players required for sustainable NRM, there is no published evidence that the not-for-profit sector is the best vehicle for the new approach to build civil society, and begs the question: where did this concept come from and what evidence was it built on? Is such a void described by Leach and Scoones [26] as assumption theory?

Glaeser [89] in an analysis of four different NGO sectors found that not-for-profit organisations have governance problems that closely resemble the corporate sector, though often more extreme. He goes on to find that in the case of wealthy not-for-profits the interests of the elite workers become quite powerful and over time the not-for-profits, which were originally dominated by donors, ultimately resemble workers' cooperatives.

A recent review of three of the largest non-profit conservation groups made two key observations: first, they had become extremely large and wealthy in a short period of time, and, second, they were promoting global approaches to conservation that led to questions and complaints from a cross section of society including local communities, national NGOs and human rights activists [90]. Chambers [27], working in Botswana, identified a common issue experienced in community-based NRM as the process by which communities obtain their constitutions. He claims that the method of establishing organisations has often been by government extension agents taking a standard constitution off the shelf and modifying a few entries, which invariably leads to a community-based organisation composed of twelve 'wise' old men who will then 'run the show like oligarchs'. Ascher [11] identified that an understanding of organisational behaviour will assist with understanding the problems that gives rise to suboptimal, unsustainable NRM. In the changing circumstances of globalisation and new policies to decentralise public services the relationship between civil society and the state is often one of competition. Baccaro [10] proposed a model of 'associational democracy' where 
Table 1: Synthesis of governance attributes of three sectors [8].

\begin{tabular}{lccc}
\hline & Government & Corporate & Not-for-profits \\
\hline Participation & $\checkmark$ & $\times$ & $\times$ \\
Transparency & $\checkmark$ & $\times$ & $\times$ \\
Responsiveness & $\checkmark$ & $\checkmark$ & $\times$ \\
Consensus orientation & $\checkmark$ & $\times$ & $\times$ \\
Equity & $\checkmark$ & $\times$ & $\times$ \\
Effectiveness & $\checkmark \times$ & $\checkmark \times$ & $\checkmark \times$ \\
Efficiency & $\checkmark \times$ & $\checkmark \times$ & $\times$ \\
Accountability & $\checkmark$ & $\checkmark$ & $\times$ \\
Strategic vision & $\checkmark$ & $\checkmark$ & $\times$ \\
Leadership & $\checkmark$ & $\checkmark$ & $\times$ \\
Regulatory framework & $\checkmark$ & $\checkmark$ & $\times$ \\
Accounting standards & $\checkmark$ & $\checkmark$ & $\times$ \\
Independent ratings/rankings of governance & $\checkmark$ & $\checkmark$ & $\times$ \\
\hline
\end{tabular}

state and civil society organisations are both part of a single, new regulatory framework that transforms both. Within this new regulatory framework the state would no longer dictate regulatory outcomes from the 'command and control' fashion, rather the state would devolve many regulatory functions to local groups and associations. The state, however, would not wither away, rather it would define the basic goals of public policy, select the social actors to participate in policy (based on their potential contribution), encourage the organisation of under-represented interests, establish minimal standards of performance, circulate information and best practice among locales and reserve the right to intervene in the case of self-regulation failure.

\subsection{Common themes}

There are key criteria to determine good governance of any organisation. Efficient, effective and enduring organisations require: clear roles and responsibilities, participation, transparency, responsiveness, consensus orientation, equity, effectiveness and efficiency, legitimate institutions, accountability, strategic vision, an adaptive management approach and independent monitoring and evaluation.

\section{THE THIRD WAY: REGIONALISM THE NEW PANACEA}

Giddens [91] characterises regionalism as the renewal of social democracy. This approach has arisen as a response to the reforms driven by globalisation and their effects on the world socially and economically. This third way approach is often referred to as 'new regionalism' as it represents an alternative to two 'failed models' of regional development: top-down, state-led and directed approaches on the one hand and free market dominated approaches on the other. Regionalism would focus on governance rather than government, with a focus on partnerships between government, the private sector and not-for-profit organisations [92]. Regionalism in this discussion refers to sub-national areas known as regions that may be defined in different ways depending on the spatial scope and objectives of the intervention policy [93]. Regions are regarded as significant in that it is the level where social organisation, institutional interaction and coordination can be more adaptive. 
The main benefits identified of a regional approach are the opportunity for meshing processes of community participation with the broader scales of government. In Australia, regionalism is seen as a strategic approach to facilitate sustainable NRM at a local level.

\subsection{Common themes}

Theory and practice demonstrate that effective, efficient and enduring sustainable NRM requires the following attributes of regionalism: successful decentralisation strategies, all forms of decentralisation to be present and clear unambiguous objectives of the intervention strategy to facilitate regionalism. Monitoring and evaluation of intervention strategies that include before and after evaluations and the anticipated performance in the absence of the intervention are key requirements to enable measurement of the success of the intervention strategy while including a flexible and adaptive management approach [8].

\section{7 'MEANS' AND 'ENDS' IN A SUSTAINABLE NRM SYSTEM}

Many authors refer $[1,4,38,54-56,58,61,67]$ to the need to build the capacity of governmental, corporate and civil society sectors to enable sustainable regional NRM; however, there is a divergence of assumptions of what are the 'means' and what are the 'ends'. Assumptions about people and their attitudes, organisations and their governance, and regional decentralisation can produce a variety of regimes where tools themselves are often confused with 'ends'. 'Means' refer to the methods, processes and instruments that are required to achieve an outcome (ends) and for sustainable regional NRM 'means' come in many forms including management systems and tools. Australia's past attempts at sustainable NRM show that awareness and activity do not necessarily equate to outcomes. McDonald [94] warns of the concerns that the present evolving regional NRM arrangements in Australia appear to be focussed again on outputs rather than outcomes.

\section{THE HYPOTHESISED MODEL}

From this review of theory and practice a model (Fig. 1) to progress the development of a sustainable regional NRM system has been developed. This model presents a process that is based on the success attributes (Table 2) from this review.

The essential foundation success attributes from organisations and their governance and regionalism are considered the building blocks of the model. On this foundation are the agent-based interactions necessary for success and the 'means' to achieve this in the form of tools and management systems. The 'end' result would then be resilient sustainable ecosystems, sustainable communities and a decentralised democracy. People and attitudes drive sustainable NRM outcomes and the behavioural changes that are required. A sustainable regional NRM system must ensure that all of the NRM players and agents (and their interactions) are included in the change management process. Clarification of roles, responsibilities, duties and rights, as has been reiterated throughout this review, are required to progress further in the regional NRM change management process. True regionalism requires a self-determined region to be identified by the communities within it, and decentralisation can only occur with long time frames, adequate social capital and legitimate transfer of powers, resources and investment. The institutional arrangements for facilitating sustainable regional NRM need to be credible and legitimate and have the underpinnings of good governance. As discussed previously, there is some evidence and a sound basis in theory to assert that people and their attitudes drive sustainable regional NRM and this needs to be viewed and managed as a conflict. The resultant interactions of agents, particularly in an environment of conflict, lead to power transfers, which can result in a number of outcomes that can impede or expedite progress towards sustainable regional 


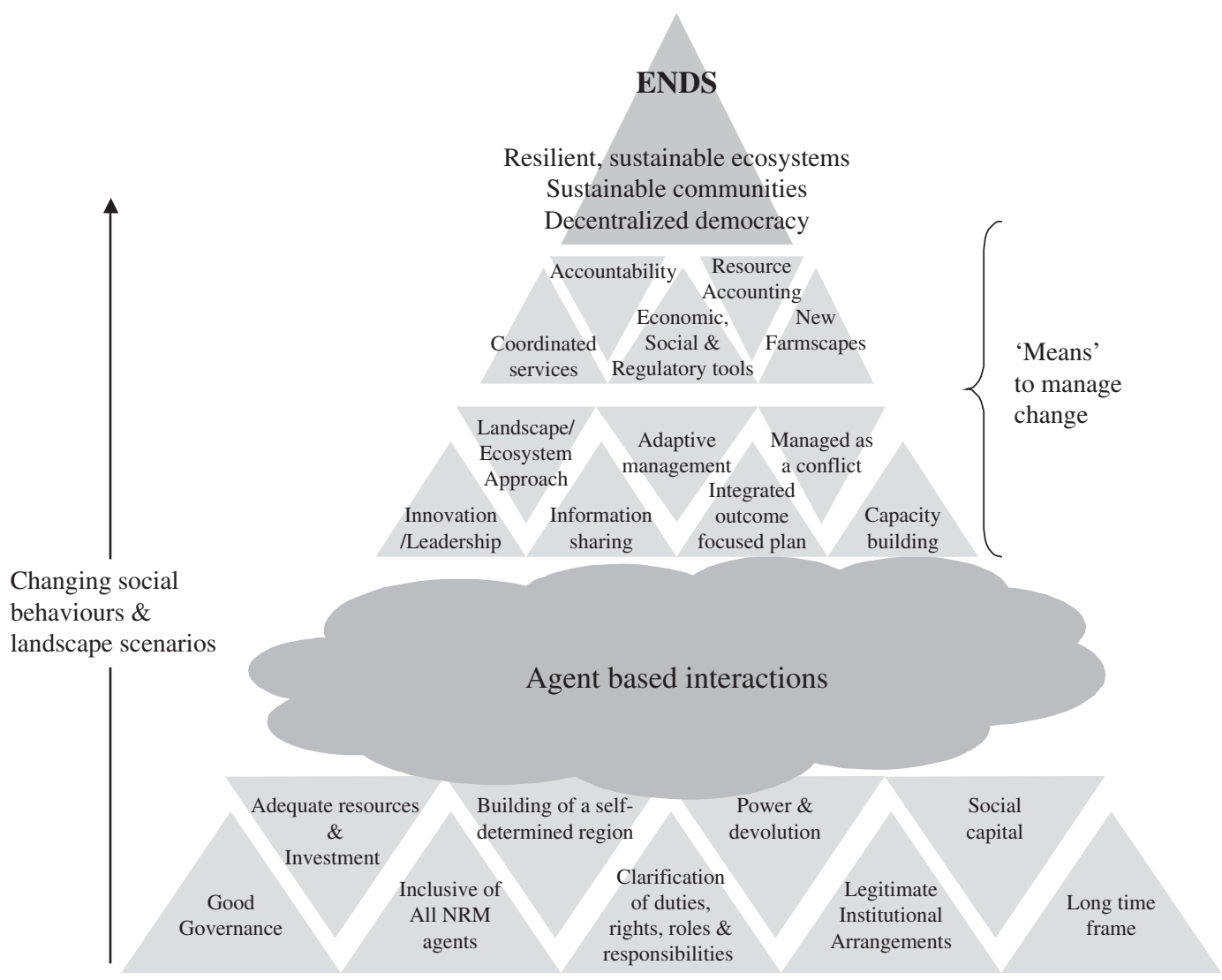

Foundation attributes of Regional NRM

Figure 1: Proposed model for a sustainable, regional NRM system [8].

NRM. The foundation attributes of good governance and regionalism, the agent interactions required, and the tools and management systems to assist the progression include the change management process itself, managing social behaviours and guiding landscape scenarios in the transaction from 'means' to 'ends'. Figure 1 provides a first rendition of the model. This model will test the current regional NRM system approaches in Australia using the massive national experiment represented by NHT2 and NAP. A diversity of approaches is already evident.

\section{CONCLUSION}

Australia appears to be caught within a 'ritual' driven action cycle as demonstrated by past and present attempts to achieve sustainable regional NRM. 'Rituals' can come in the form of habits, routines, conventions and traditions and, as Dover [95] has observed, can emerge as being perceived as adhockery and amnesia. The identification of Australia's optional obligatory approach as presented in this paper ranging from soil erosion in the early 1900s to regional NRM approaches in the 21 st century indicates that Australia may be experimenting with a mix of 'means' and 'rituals' and construing these as achieving 'ends' and outcomes in sustainable regional NRM. This view 
Table 2: Success attributes of key elements.

\begin{tabular}{ll}
\hline International NRM & Organisations and their governance \\
Stakeholders and their communities & Clear roles and responsibilities \\
Organisations and their governance & Participation \\
Power relations & Transparency \\
Conflicts of interest & Responsiveness \\
Negotiation processes & Consensus orientation \\
Participatory processes & Equity \\
NRM in Australia & Effectiveness and efficiency \\
Duty of care & Legitimate institutions \\
Property rights & Accountability \\
People and their interactions & Strategic vision \\
Power relations & Adaptive management approach \\
Legitimate organisations & Independent monitoring and evaluation \\
Participatory processes & Adequate resources \\
People and attitudes & Regionalism \\
Inclusive of all players and agents & Self-determined region \\
Power relations & Decentralisation strategies \\
Conflict management & Clear intervention strategies \\
Adaptive management approach & Monitoring and evaluation \\
Long time frames & Adaptive management approach \\
& Devolution \\
& Social capital \\
& Means and ends \\
& Economic, social and environmental tools \\
&
\end{tabular}

is supported by the repetitive findings of NRM programme reviews since the early 1990s [8]. This dilemma of confusion of 'means' and 'ends' presents an opportunity for the development of a model of sustainable NRM informed from theory and practice to redress the current Australian NRM ritual driven approach. The model presented in Fig. 1 clearly defines the 'means' and 'ends' to achieve sustainable regional NRM in Australia, providing an evaluative tool to appraise the current regional NRM systems. This model informed the design and execution of an independent evaluation undertaken from 2004 to 2006 of the regional NRM systems in Australia. Use of the model for evaluative purposes provides guidance for future regional NRM intervention systems design to ensure that effective, efficient and enduring NRM is achieved.

\section{REFERENCES}

[1] National Natural Resource Management Task Force, Managing Natural Resources in Rural Australia for a Sustainable Future, Canberra, 1999.

[2] World Bank, Natural Resources Management, http://lnweb18.worldbank.org/essd/essd.nsf/ GlobalView/NRM.pdf/\$File/NRM.pdf, Washington, DC 2000.

[3] Lawrence, G.A., Higgins, V. \& Lockie, S., Environment, Society and Natural Resource Management, Edward Elgar: Cheltenham, 2001. 
[4] Rasmussen, L.N. \& Meinzen-Dick, R., Local organizations for natural resource management lessons from theoretical and empirical literature. IFPRI Environment \& Production Technology Discussion Paper 11, Washington, DC, 1995.

[5] Lachapelle, P.R., McCool, S.F. \& Patterson, M.E., Barriers to effective natural resource planning in a 'messy' world. Society \& Natural Resources, 16(6), pp. 473-490, 2003.

[6] Avery, S.K., Resource management decision support. The CCSP Plan Climate Change Science Program Workshop, Colorado, 2002.

[7] Farrington, J. \& Baumann, P., Panchayati Raj and Natural Resource Management: How to Decentralise Management over Natural Resources, Overseas Development Institute: London, 2000.

[8] Williams, J.A., PhD Dissertation, Brisbane, Australia, 2007.

[9] Centre for Future Studies, www.futurestudies.co.uk, 2004.

[10] Baccaro, L., Civil society meets the state: a model of associational democracy. International Labour Office Working Paper No. DP/138, Geneva, 2002.

[11] Ascher, W., Coping with complexity and organizational interests in natural resource management. Ecosystems, 4(8), pp. 742-757, 2001.

[12] Millennium Ecosystem Assessment Board, Living Beyond our Means: Natural Assets and Human Well-Being, www.millenniumassessment.org/en/index.aspx, 2005.

[13] Brown, R.L., Rescuing a Planet under Stress and a Civilization in Trouble, Norton \& Company: New York, 2003.

[14] Stewart, K., Avoiding the tragedy of the commons: greening governance through the market or the public domain? The Market or the Public Domain: Global Governance and the Asymmetry of Power, ed. D. Drack, Routledge: New York, 2001.

[15] Hardin, G., The tragedy of the commons. Science, 162(3859), pp. 1243-1248, 1968.

[16] Institute for the Study of Society and the Environment, Ecosystem Sustainability Project: The Tragedy of the Commons, www.isse.ucar.edu, 2003.

[17] Paul Lee, M., Community-Based Natural Resource Management: A Bird's Eye View, IDRC: Ottawa, 2002.

[18] Holling, C.S., Adaptive Environmental Assessment and Management, John Wiley: New York, 1978.

[19] Holling, C.S. \& Meffe, G.K., Command and control and the pathology of natural resource management. Conservation Biology, 10(2), pp. 328-337, 1996.

[20] International Workshop on Community-Based Natural Resource Management, Workshop Report, www.worldbank.org/wbi/conatrem/, The World Bank: Washington, DC, 1998.

[21] Ribot, J.C., Democratic Decentralisation of Natural Resources: Institutionalising Popular Participation, World Resources Institute: Washington, DC, 2002.

[22] Ostrum, E., How inexorable is the tragedy of the commons? Institutional arrangements for changing the structure of social dilemmas. Distinguished Faculty Research Lecture, Indiana University, Indiana, 1986.

[23] Gunter, J. \& Jodway, S., Community-based natural resource management: a strategy for community economic development. Draft, CED for Forest Communities Project, Canada, 1999.

[24] Johnson, C., Local democracy, democratic decentralisation and rural development: theories, challenges and options for policy. Development Policy Review, 19(4), pp. 521-532, 2001.

[25] Engel, S. \& Sikor, T., Devolution and local participation in resource management. Proceedings of a Roundtable Discussion at Deutscher Tropentag, Göttingen Humboldt University Berlin, 2003. 
[26] Leach, M. \& Scoones, I., The institutional dynamics of community-based natural resource management: an entitlements approach. Institute of Development Studies, University of Sussex, 2000.

[27] Chambers, L., An act of faith: community based natural resource management in Botswana, http://www.iucn.org/en/news/archive/2001_2005/press/botswanachambers.pdf, Botswana, 2001.

[28] Pender, J. \& Scherr, S.J., Organisational development and natural resource management: evidence from Central Honduras. EPTD Discussion Paper 49, International Food Policy Institute, Washington, DC, 1999.

[29] Birner, R., Analyzing negotiation approaches in natural resource management - a case study of crop-livestock conflicts in Sri Lanka. 25th International Conference of Agricultural Economists, Durban, 2003.

[30] Hare, M., Letcher, R.A. \& Jakeman, A.J., Participatory natural resource management: a comparison of four case studies. Proceedings of the First Biennial Meeting of the International Environmental Modelling and Software Society, iEMSs, Manno, Switzerland, 2002.

[31] Knox, A. \& Meinzen-Dick, R., Collective action, property rights and devolution of natural resource management: exchange of knowledge and implications for policy. CAPRi Working Paper No. 11, IFPRI, Washington, DC, 2001.

[32] McLain, R. \& Jones, E., Challenging 'community' definitions in sustainable natural resource management: the case of wild mushroom harvesting in the USA. Gatekeeper Series No. 68, IIED, London, 1997.

[33] Adger, N., Brown, K., Fairbrass, J., Jordan, A., Paavola, J., Rosend, S. \& Seyfang, G., Governance for sustainability, towards a 'thick' understanding of environmental decision making. CSERGE Working Paper EDM 02-04, CSERGE, Norwich, UK, 2004.

[34] Timmer, V., Community-based conservation and leadership: frameworks for analysing the equator initiative. CID Graduate Student Working Paper No. 2, Science, Environment and Development Group, Centre for International Development, Harvard University, Cambridge MA, 2004.

[35] Meynen, W. \& Doornbos, M., Decentralising natural resource management: a recipe for sustainability and equity? European Journal of Development Research, 16(1), pp. 235-254, 2004.

[36] Lane, M.B. \& McDonald, G., Community-based environmental planning: operational dilemmas, planning principles and possible remedies. Journal of Environmental Planning and Management, 48(5), pp. 709-731, 2005.

[37] Prime Minister's Science, Engineering and Innovation Council (PMSEIC), Moving Forward in Natural Resource Management Report, Canberra, Australia, 1999.

[38] Dunlap, T.R., Nature and the English Diaspora, Cambridge University Press: Cambridge, 1999.

[39] Campbell, A., Landcare Communities Shaping the Land and the Future, Allen \& Unwin: Sydney, 1994.

[40] Cary, J.W. \& Webb, T., Landcare in Australia: community participation and land management. Journal of Soil and Water Conservation, 56(4), pp. 274-278, 2001.

[41] Hutton, D. \& Connors, L., A History of the Australian Environment Movement, Cambridge University Press: Cambridge, 1999.

[42] Bolton, G., Spoils and Spoilers: Australians Make Their Environment, 1788-1980, Allen \& Unwin: Sydney, 1988.

[43] Heathcote, R.L. \& Mabutt, J.A., Land, Water and People: Geographical essays in Australian Resource Management, Allen \& Unwin: Sydney, 1988. 
[44] Mulligan, M. \& Hill, S., Ecological Pioneers, Cambridge University Press: Cambridge, 2001.

[45] Dovers, S. (ed.), Environmental History and Policy: Still Settling, Oxford University Press: Melbourne, Australia, 2000.

[46] Australian Landcare Council, The future of landcare. Discussion paper, Canberra, 2001.

[47] Blake, J., Landcare, where has it come from and where to now? National Landcare Conference Proceedings, Darwin, 2003.

[48] Kirner, J., Radio interview, Australian Broadcasting Corporation, www.abc.net.au/rn/science/ earth/stories/s112638.htm, 2000.

[49] Flannery, T., Beautiful Lies, Black Inc.: Melbourne, 2003.

[50] Lloyd, B., Landcare: a community based approach to sustainable development. Proceedings of the IFA Annual Conference, Sydney, 2001.

[51] Australian Government Department of Agriculture, Fisheries \& Forestry, Natural Heritage Trust Phase 1 Final Evaluation: Scope and Terms of Reference, Canberra, 2003.

[52] Business Leaders Roundtable, Repairing the Country: Leveraging Private Investment, Allen Consulting Group: Sydney, 2001.

[53] National Farmers Federation/Australian Conservation Foundation, National Investments in Rural Landscapes, The Virtual Consulting Group \& Griffin NRM Pty Ltd: Canberra, 2000.

[54] Australian State of the Environment Committee, State of the Environment, CSIRO Publishing: Collingwood, 2001.

[55] Wentworth Group, Blueprint for a Living Continent, WWF: Australia, 2002.

[56] Industry Commission, A Full Repairing Lease: Inquiry into Ecologically Sustainable Land Management, Commonwealth of Australia: Canberra, 1998.

[57] Standing Committee on Environment \& Heritage, Public good conservation: our challenge for the 21st century. Parliamentary paper 231/2001, Canberra, 2001.

[58] National Land \& Water Audit, www.nlwra.gov.au, 2004.

[59] NRM National Steering Committee, A discussion paper for developing a national policy, Canberra, 2000.

[60] Australian National Audit Office, Performance Information for Commonwealth Financial Assistance under the Natural Heritage Trust, Commonwealth of Australia: Canberra, 2001.

[61] Hassall \& Associates, Natural Heritage Trust Phase 1 Final Evaluation, A report prepared for the Department of Agriculture, Fisheries and Forestry and the Department of Environment and Heritage, Canberra, 2005.

[62] Australian National Audit Office, The Administration of the National Action Plan for Salinity and Water Quality, The Auditor General Audit Report No. 17, Canberra, 2004.

[63] Bennett, D., Rethinking community-based integrated catchment management. Paper presented at the 47th Annual Conference of the Australian Agricultural and Resource Economics Society, Fremantle, Western Australia, 2003.

[64] Lane, M.B., McDonald, G.T. \& Morrison, T.H., Decentralisation and environmental management in Australia: a comment on the prescriptions of the Wentworth Group. Australian Geographic Studies, 42(1), pp. 103-115, 2004.

[65] Moore, S.A., Regional delivery of natural resource management in Australia: it is democratic and does it matter? Paper presented for the Academy of the Social Sciences in Australia Workshop, RMIT Hamilton Victoria Participation and Governance in Regional Development, 2004.

[66] McDonald, G. \& Morrison, T., Integrating natural resource management systems for better environmental outcomes. Paper for the Australian Water Summit, Sydney, 2003. 
[67] Yee, S. \& Rolfe, J., Institutional choices for natural resource management: judging the efficiency of NRM bodies. Paper presented at the International Conference on Engaging Communities, Brisbane, Australia, 2005.

[68] McDonald, G., Taylor, B., Bellamy, J., Robinson, C., Walker, M., Smith, T., Hoverman, S., McAlpine, C., Peterson, A. \& Dawson, S., Benchmarking Regional Planning Arrangements for Natural Resource Management 2004-05: Progress, Constraints and Future Directions for Regions, Milestone Report 3, Tropical Savannas Management CRC, Brisbane, 2005

[69] Australian Bureau of Statistics, Natural Resource Management on Australian Farms 2004-05, Australian Bureau of Statistics: Canberra, 2007.

[70] Richards, R., National Monitoring and Evaluation Trials Phase II Synthesis, National Land \& Water Resources Audit, Canberra, 2005.

[71] Australian Government Productivity Commission, Impacts of Native Vegetation and Biodiversity Regulations Report, Melbourne, Australia, 2004.

[72] Davidson, A. \& Elliston, L., Regulation and farm viability: a case study in north-west New South Wales. Australian Commodities, 12(10), pp. 200-207, 2005.

[73] Beeton, R.J.S. (Bob), Buckley, K.I., Jones, G.J., Morgan, D., Reichelt, R.E. \& Trewin, D. (2006 Australian State of the Environment Committee), Australia State of the Environment 2006, Independent report to the Australian Government Minister for the Environment and Heritage, Department of the Environment and Heritage, Canberra, 2006.

[74] Pahl-Wostl, C., Agent based simulations in integrated assessment and resources management. Paper presented at proceedings of International Environmental Modelling and Software Society, Lugano, Switzerland, 2002.

[75] Doran, J., Intervening to achieve co-operative ecosystem management. Journal of Artificial Societies and Social Stimulation, 4(2), 2001.

[76] Ross, D., Game theory. The Stanford Encyclopaedia of Philosophy, Spring edition, ed. Edward N. Zalta, http://plato.stanford.edu/archives/spr2006/entries/game-theory/, 2006.

[77] DeRosis, F., How to consider personality factors in simulating a reasonable and natural behaviour of agents? I3 Spring Days Workshop Proceedings, Sitges, Spain, 1999.

[78] Skvoretz, J., Complexity theory and models for social networks. Complexity, 8(1), pp. 47-55, 2003.

[79] Howard, P.J. \& Howard, J.M., An introduction to the five-factor model of personalities for human resource professionals. Centre for Applied Cognitive Studies, North Carolina, 2004.

[80] Conte, R. \& Dignum, F., From social monitoring to normative influence. Journal of Artificial Societies and Social Stimulation, 4(2), 2001.

[81] Barzilai, K., Organizational theory, Case Western Reserve University Cleveland, 2003.

[82] Wilson, E., In Search of Nature, Penguin Press London, 1996.

[83] Ratzburg, W., Organisational Behaviour, British Columbia Institute of Technology: Burnaby, Canada, 2004.

[84] Wilkinson, D., Civilisations as networks: trade, war, diplomacy and command control. Complexity, 8(2), pp. 82-86, 2003.

[85] Carter, R.W. \& Beeton, R.J.S., A model of cultural change and tourism. Asia Pacific Journal of Tourism Research, 9(4), pp. 423-441, 2004.

[86] Ostrum, E., Understanding Institutional Diversity, Princeton University Press: Princeton and Oxford, 2005.

[87] International Development Research Centre, Readings on institutional analysis. CBNRM Social Science Resource Kit, IDRC: Canada, 2001. 
[88] Cabus, P., Governance in Flanders regional policy: subregional platforms as development coalitions. Paper present at the Regional Studies Association International Conference, Pisa, Italy, 2003.

[89] Glaeser, E.L., The governance of not-for-profit firms. Working Paper 8921, National Bureau of Economic Research, Cambridge, MA, 2002.

[90] Chapin, M., A challenge to conservationists. World Watch Magazine, November/December, 2004.

[91] Giddens, A., The Third Way: The Renewal of Social Democracy, Polity Press: Cambridge, 1998.

[92] Rainnie, A., New regionalism in Australia: limits and possibilities. Proceedings of the Social Inclusion and New Regionalism Workshop, Brisbane, 2002.

[93] Bureau of Transport and Regional Economics, Government interventions in pursuit of regional development: learning from experience. Working Paper 55, Canberra, 2003.

[94] McDonald, G., Regional NRM: what is in place and why? Proceedings of the EIANZ Seminar, Brisbane, 2003.

[95] Dovers, S., Institutions for sustainability. Tela Series, Issue 7, Australian Conservation Foundation, Canberra, 2001. 